\title{
Comparison of radial and meander-like breast ultrasound with respect to diagnostic accuracy and examination time
}

\author{
Claudia Jäggi-Wickes ${ }^{1} \cdot$ Pascale Brasier-Lutz ${ }^{1} \cdot$ Sabine Schaedelin $^{2} \cdot$ Rosemarie Burian $^{1}$. \\ Cora-Ann Schoenenberger ${ }^{3,4} \cdot$ Rosanna Zanetti-Dällenbach ${ }^{4}$ (1)
}

Received: 27 August 2019 / Accepted: 20 April 2020 / Published online: 3 May 2020

(c) The Author(s) 2020

\begin{abstract}
Purpose To prospectively compare the diagnostic accuracy of radial breast ultrasound (r-US) to that of conventional meander-like breast ultrasound (m-US), patients of a consecutive, unselected, mixed collective were examined by both scanning methods.

Methods Out of 1948 dual examinations, 150 revealed suspicious lesions resulting in 168 biopsies taken from 148 patients. Histology confirmed breast cancers in 36 cases. Sensitivity, specificity, accuracy, PPV, and NPV were calculated for r-US and $\mathrm{m}$-US. The examination times were recorded.

Results For m-US and r-US, sensitivity (both $88.9 \%$ ), specificity ( $86.4 \%$ versus $89.4 \%$ ), accuracy ( $86.9 \%$ versus $89.3 \%$ ), PPV (64.0\% versus 69.6\%), NPV (both 98.3\%), false-negative rate (both 5.6\%), and rate of cancer missed by one method (both 5.6\%) were similar. The mean examination time for r-US $(14.8 \mathrm{~min})$ was significantly $(p<0.01)$ shorter than for $\mathrm{m}$-US (22.6 min).

Conclusion Because the diagnostic accuracy of r-US and m-US are comparable, r-US can be considered an alternative to $\mathrm{m}$-US in routine breast US with the added benefit of a significantly shorter examination time.
\end{abstract}

Keywords Diagnostic accuracy $\cdot$ Ductosonography $\cdot$ Examination time $\cdot$ False negative $\cdot$ Meander-like breast ultrasound . Radial breast ultrasound

Part of the data was recently presented at the 42 . Dreiländertreffen SGUM, DEGUM, ÖGUM with an abstract published in Ultraschall in Med 2018; Vol.39, Supplement 1 p43 and at the 16th St. Gallen International Breast Cancer Conference with an abstract published in The Breast Vol. 44, Supplement 1, pS48.

Rosanna Zanetti-Dällenbach

rosanna.zanetti@claraspital.ch

1 Department of Obstetrics and Gynecology, University Hospital Basel, Spitalstrasse 21, 4056 Basel, Switzerland

2 Department of Clinical Research, Statistics and Data Management, University Basel, Schanzenstrasse 55, 4031 Basel, Switzerland

3 Department of Chemistry, University Basel, BioPark 1096, Mattenstrasse 24a, 4058 Basel, Switzerland

4 Gynecology/Gynecologic Oncology, St.Claraspital Basel, Kleinriehenstrasse 30, 4002 Basel, Switzerland

\section{Introduction}

In conventional breast ultrasound (US), the probe is typically moved in a meander-like manner in two orthogonal planes. Although this reveals the specific breast structures at different angles, it does not show them in their anatomical context, whereas radial breast ultrasound visualizes the entire extension of the anatomic structures of the breast, specifically ducts and lobules. Also, the nipple-areola complex, which often poses a diagnostic problem due to acoustic shadowing produced by the intricacy of the anatomic structures [1-3] can easily be delineated.

Radial breast ultrasound (r-US), also called ductosonography, was introduced by Rosensweig et al. [1]. It is mostly used in case of nipple discharge $[4,5]$ to examine dilated ducts and to visualize intraductal papillomas or other intraductal pathologies [6] in combination with conventional meander-like ultrasound (m-US). However, r-US is usually not applied on its own in routine clinical practice, mainly due to the width constraints of conventional probes 
$(50 \mathrm{~mm})$ which do not allow an efficient radial screening of the breast. Even after a wider probe $(92 \mathrm{~mm})$ became commercially available, the number of institutions or examiners performing r-US as routine breast ultrasound procedure remained limited although a number of authors and institutions consider $\mathrm{r}$-US a viable alternative to $\mathrm{m}$-US $[3,7,8]$. Consequently, only a handful of studies have been published where breast ultrasound was performed by radial and not by meander-like scanning [9-13]. However, to the best of our knowledge, the two scanning techniques have so far not been directly compared. In addition, diagnostic accuracy of r-US and the duration of the examination have not yet been comprehensively investigated. Therefore, we here compare the examination time and diagnostic accuracy between radial and meander-like scanning in the detection rate of malignant breast lesions, which were confirmed by histology.

\section{Materials and methods}

Following approval by the local ethical committee (EKBB Nr. 123/11), we conducted this prospective single-center study from August 2011 to August 2014. The study included symptomatic women presenting with breast pain or palpable breast lumps, asymptomatic women with increased risk for breast cancer or women with dense breast tissue, and women with a history of breast cancer. Women younger than 18 years of age and women scheduled for minimal invasive breast biopsies were excluded from this study. As a result, the study comprised 1948 dual US examinations. All study participants signed the informed consent form in accordance with the World Medical Association Declaration of Helsinki.

Women of an unselected, consecutive, mixed collective were examined by conventional m-US and r-US on the same day by different examiners. Demographic data collection and physical breast examination were performed before the ultrasound examinations. All study subjects received a complete, bilateral r-US and m-US in random order, each of which was performed by independent examiners. Both examiners had full knowledge of the clinical findings, and where available, of mammographic results. However, the findings of the US examination were masked to the other examiner.

A designated research fellow specialized in gynecology and obstetrics but with limited prior experience in breast US performed all r-US. In addition to a yearly training in breast US that all examiners received, the research fellow received a theoretical and practical didactic training in $\mathrm{r}-\mathrm{US}$ before study begin. M-US was performed by experts or, in the case of inexperienced examiners, under the supervision of an expert, as is common in teaching hospitals.

The r-US and $\mathrm{m}$-US examinations were performed using two ultrasound machines of the same type (EUB-7500 V 16-53 Step 3.5, Hitachi; Hitachi Medical Systems Europe
Holding AG, Zug, Switzerland). The m-US was performed with a $50 \mathrm{~mm}$ wideband, high-frequency (13-5 MHz) linear probe (EUP-L74M; Hitachi Medical Systems Europe Holding AG, Zug, Switzerland) and the r-US with a $92 \mathrm{~mm}$ wideband (10-5 MHz) linear probe (EUP-L53L; Hitachi Medical Systems Europe Holding AG, Zug, Switzerland) protected by a water-filled latex cover according to the manufacturer's instructions (Hitachi Medical Systems Europe Holding AG, Zug, Switzerland). Each US examination was separately documented in the electronic patient records (ViewPoint ${ }^{\circledR}$, Version 5; GE Healthcare GmbH, Munich, Germany).

To determine the duration of the examination, we recorded an image with a timestamp at the beginning and at the end of the ultrasound examination.

Both breast US examinations were conducted with the woman lying in the same oblique supine position with her ipsilateral arm raised and her hand placed behind the head to flatten the breast tissue. R-US was performed as described by Teboul [14]. In brief, the probe was first moved clockwise around the nipple in a radial fashion (Fig. 1a, upper left panel). Then the upper outer quadrant of the breast was swept radial and anti-radial to explore the axillary tail. Finally, the probe was moved perpendicular to the ducts (anti-radial scan; Fig. 1a, upper right panel). For m-US, scanning was performed in two orthogonal planes with a meander-like probe movement (Fig. 1b) for each plane. Scanning of the axilla was routinely included. Representative ultrasound images for each method are shown in the bottom panels of Fig. 1.

We determined the dimensions of each sonographic lesion based on recordings in two orthogonal directions. Size, localization, morphologic characteristics of the lesion,
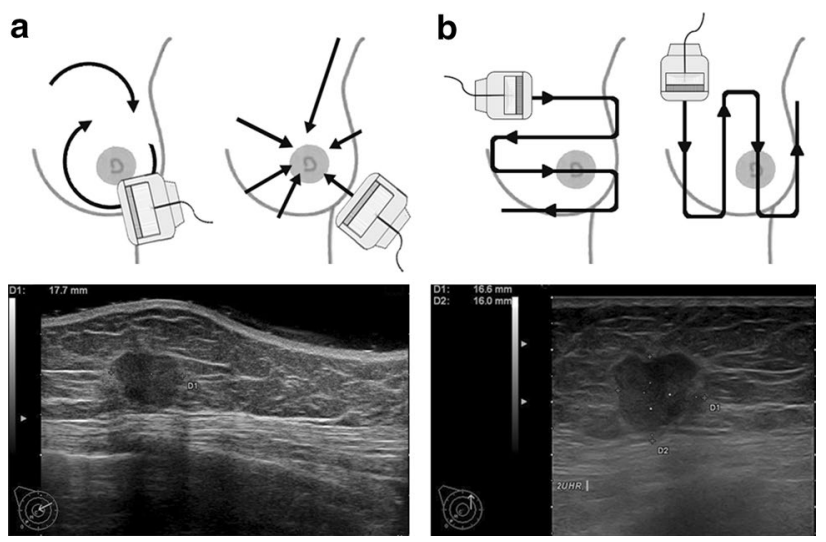

Fig. 1 Radial and meander-like ultrasound. a Scheme of radial scanning movement (top) and corresponding ultrasound image (bottom). Left panel: radial movement and radial movement for the axillary tail; right panel: anti-radial movement. b Scheme of meander-like scanning movement in two orthogonal planes (top) and corresponding ultrasound image (bottom). Both ultrasound images are from the same 59-year-old patient diagnosed with invasive ductal breast cancer 
and their BI-RADS classification according to the BI-RADS Atlas [15] were documented in the electronic patient records.

Breast lesions characterized as BI-RADS 4 or 5 and as BI-RADS 3 in case of an increased risk, were biopsied (sonographic-guided fine needle aspiration, core needle biopsy or vacuum-biopsy) and a cytologic or histopathologic diagnosis was obtained.

All data on patient and lesion characteristics extracted from the electronic patient records were entered into $R$ (R Development Core Team 2018, Vienna, Austria) for data analysis.

\section{Statistical methods}

Age, family history, and personal history were summarized in relation to the diagnosis. Family and personal histories are presented as frequencies and percentages. For the patient age, the mean and standard deviation were calculated and the minimum and maximum values were determined. The difference between benign and malignant lesions for different patient characteristics was compared using $t$ and Chi-square tests. The length of the examination was calculated from the timestamp on the US image recorded at the beginning and at the end of the respective bilateral ultrasound examination. Examination time was compared between m-US and r-US using a Wilcoxon signed-rank test with continuity correction.

The results from the histology served as gold standard. Where lesions were missed by r-US or by m-US, the lesions were considered normal breast tissue and were interpreted accordingly for statistical analysis. For both methods, the sensitivity, specificity, and accuracy were calculated with 95\% confidence intervals (CIs). The CIs were estimated according to Blaker [16]. $P$ values were calculated using the exact McNemar's test [17]. Positive and negative predictive values were calculated together with corresponding 95\% CIs, and the respective $p$ values were calculated [17]. The negative predictive value was calculated either including or excluding missed cancers. Only lesions described by both methods were compared for $p$ value calculation.

The proportion of true positive, false negative, and cancers missed by one of the scan methods were calculated for malignant lesions. Correspondingly, the proportion of true negative and false positive, and the proportion of benign lesions not revealed were calculated for benign lesions. For data comparison between the two scan methods, an exact McNemar's test was used.

Lesions from the same subject were considered independent. All analyses were performed by $R$. No correcting for multiple testing was performed.

\section{Results}

We performed 2327 US examinations including both, r-US and $\mathrm{m}$-US. We excluded 379 examinations ( 2 examinations in male patients, 18 examinations of patients younger than 18 years, 56 incomplete US examinations, 128 incomplete informed consent forms, and 175 incomplete datasets). Out of the remaining 1948 eligible dual US examinations, 150 (7.7\%) ultrasound examinations of 148 patients revealed 168 suspicious lesions. Breast cancers were diagnosed in 36 lesions (1.8\%). Because the remaining 1798 dual US examinations revealed no or unsuspicious lesions, no biopsy was performed.

Table 1 summarizes the general patient characteristics of the study population. Patients with no or no suspicious

Table 1 Patient characteristics

\begin{tabular}{|c|c|c|c|c|c|c|}
\hline & \multicolumn{3}{|l|}{ All study subjects } & \multicolumn{3}{|c|}{ Patients with suspicious breast lesions $(n=148)$} \\
\hline & $\begin{array}{l}\text { No or no suspicious } \\
\text { breast lesions }\end{array}$ & Suspicious breast lesions & $p$ value & Benign histology & Malignant histology & $p$ value \\
\hline Number of patients $(\%)$ & $1251(100)$ & $148(100)$ & & $115(100)$ & $33(100)$ & \\
\hline $\begin{array}{l}\text { Mean age in years }(\min , \max ) \\
{[ \pm \mathrm{SD}]}\end{array}$ & $\begin{array}{c}48.7(18,88) \\
{[ \pm 14.3]}\end{array}$ & $47.1(19,86)[ \pm 14.7]$ & 0.229 & $\begin{array}{c}44.1(19,86) \\
{[ \pm 14.0]}\end{array}$ & $57.8(30,79)[ \pm 12.1]$ & $<0.01$ \\
\hline $\begin{array}{l}\text { Personal history of breast } \\
\text { cancer }(\%)\end{array}$ & $47(3.8)$ & $3(2.0)$ & 0.402 & $2(1.7)$ & $1(3.0)$ & 0.520 \\
\hline Negative family history (\%) & $894(71.5)$ & $95(64.2)$ & 0.081 & $74(64.3)$ & $21(63.6)$ & 0.485 \\
\hline Positive family history (\%) & $357(28.5)$ & $53(35.8)$ & & $41(35.7)$ & $12(36.4)$ & \\
\hline Breast cancer & 319 & 43 & & 32 & 11 & \\
\hline Ovarian cancer & 1 & 2 & & 2 & 0 & \\
\hline Breast and ovarian cancer & 14 & 2 & & 1 & 1 & \\
\hline Endometrial cancer & 10 & 6 & & 6 & 0 & \\
\hline Breast and endometrial cancer & 13 & 0 & & 0 & 0 & \\
\hline
\end{tabular}


breast lesion had a mean age of 48.7 years, while those with a suspicious breast lesion a mean age of 47.1 years. Of the latter, women diagnosed with breast cancer had a mean age of 57.8 years and were significantly $(p<0.001)$ older than women with a benign diagnosis who had a mean age of 44.1 years. The incidence of a positive personal history of breast cancer or positive family history in patients with suspicious lesions and patients with no or no suspicious lesions that did not require a breast biopsy was similar.

All 168 suspicious lesions, 73 (43.5\%) of which were clinically palpable, were clarified by sonographic guided fine needle aspiration $(n=10,6.0 \%)$, core needle biopsy ( $n=146,86.9 \%)$, or vacuum biopsy $(n=12,7.1 \%)$. The histopathologic/cytologic diagnoses revealed a malignancy in $21.4 \%(n=36)$ and a benign histology in $78.6 \%(n=132)$ of the lesions. The benign histologies comprised 6 (4.5\%) B3 lesions, 50 (37.9\%) fibroadenomas, 41 (31.1\%) cases with fibrosis/sclerosis, and 35 (26.5\%) other benign findings. All 36 carcinomas were diagnosed based on a core needle biopsy. Two (5.6\%) ductal carcinoma in situ (DCIS), three $(8.3 \%)$ invasive lobular carcinomas, and 31 (86.1\%) invasive ductal carcinomas were identified. The final BIRADS assessment based on m-US and r-US for all benign and malignant lesions and information whether or not the lesion was palpable or visible on mammographic images is presented in Table 2.

As indicated by the asterisk in Table 2, two of the 36 breast cancers were falsely characterized as BI-RADS 3 by $\mathrm{r}$-US and $\mathrm{m}$-US (one DCIS and one triple negative invasive ductal carcinoma). This corresponds to a false-negative rate of $5.6 \%$.

Two other breast cancers were missed by m-US but correctly identified by $\mathrm{r}$-US whereas two different breast cancers were missed by $r$-US but correctly identified by m-US

Table 2 Findings of clinical palpation and mammography and final BI-RADS assessment for benign and malignant breast lesions

\begin{tabular}{|c|c|c|c|c|c|c|c|c|c|}
\hline & \multicolumn{4}{|c|}{ Malignant lesions } & \multicolumn{5}{|c|}{ Benign lesions } \\
\hline & $\begin{array}{l}\text { Malignant } \\
\text { lesions }\end{array}$ & $\begin{array}{l}\text { Invasive } \\
\text { ductal }\end{array}$ & $\begin{array}{l}\text { Invasive } \\
\text { lobular }\end{array}$ & DCIS & $\begin{array}{l}\text { Benign } \\
\text { lesions }\end{array}$ & B2 lesions & $\begin{array}{l}\text { Fibrosis/scle- } \\
\text { rosis }\end{array}$ & $\begin{array}{l}\text { Fibroad- } \\
\text { enoma }\end{array}$ & B3 lesions \\
\hline & $n(\%)$ & $n(\%)$ & $n(\%)$ & $n(\%)$ & $n(\%)$ & $n(\%)$ & $n(\%)$ & $n(\%)$ & $n(\%)$ \\
\hline & $36(100)$ & $31(86.1)$ & $3(8.3)$ & $2(5.6)$ & $132(100)$ & $35(26.5)$ & $41(31.1)$ & $50(37.9)$ & $6(4.5)$ \\
\hline \multicolumn{10}{|c|}{ Meander-like ultrasound } \\
\hline BI-RADS 5 & $15(41.7)$ & $12(80.0)$ & $3(20.0)$ & & $1(0.8)^{+}$ & & $1(100)$ & & \\
\hline BI-RADS 4 & $17(47.1)$ & $16(94.1)$ & & $1(5.9)$ & $17(12.9)^{+}$ & $5(29.4)$ & $7(41.2)$ & $4(23.5)$ & $1(5.9)$ \\
\hline BI-RADS 3 & $2(5.6)^{*}$ & $1(50.0)$ & & $1(50.0)$ & $104(78.7)$ & $29(27.9)$ & $30(28.8)$ & $41(39.4)$ & $4(3.9)$ \\
\hline BI-RADS 2 & $0(0.0)$ & & & & $9(6.8)$ & $1(11.1)$ & $3(33.3)$ & $5(55.6)$ & \\
\hline Missing & $2(5.6)^{\ddagger}$ & $2(100)$ & & & $1(0.8)^{\ddagger}$ & & & & $1(100)$ \\
\hline \multicolumn{10}{|c|}{ Radial ultrasound } \\
\hline BI-RADS 5 & $15(41.7)$ & $13(86.7)$ & $2(13.3)$ & & $2(1.5)^{+}$ & & $2(100)$ & & \\
\hline BI-RADS 4 & $17(47.1)$ & $15(88.2)$ & $1(5.9)$ & $1(5.9)$ & $12(9.1)^{+}$ & $2(16.7)$ & $6(49.9)$ & $2(16.7)$ & $2(16.7)$ \\
\hline BI-RADS 3 & $2(5.6)^{*}$ & $1(50.0)$ & & $1(50.0)$ & $100(75.7)$ & $27(27.0)$ & $27(27.0)$ & $42(42.0)$ & $4(4.0)$ \\
\hline BI-RADS 2 & $0(0.0)$ & & & & $15(11.4)$ & $6(40.0)$ & $5(33.3)$ & $4(26.7)$ & \\
\hline Missing & $2(5.6)^{\ddagger}$ & $2(100)$ & & & $3(2.3)^{\ddagger}$ & & $1(33.3)$ & $2(66.7)$ & \\
\hline \multicolumn{10}{|l|}{ Palpation } \\
\hline $\begin{array}{l}\text { Lesion pal- } \\
\text { pable }\end{array}$ & $23(63.9)$ & $21(91.2)$ & $1(4.4)$ & $1(4.4)$ & $50(37.9)$ & $16(32.0)$ & $9(18.0)$ & $24(48.0)$ & $1(2.0)$ \\
\hline $\begin{array}{l}\text { Lesion not } \\
\text { palpable }\end{array}$ & $8(22.2)$ & $6(75.0)$ & $1(12.5)$ & $1(12.5)$ & $73(55.3)$ & $18(24.7)$ & 29 (39.7) & $22(30.1)$ & $4(5.5)$ \\
\hline Missing & $5(13.9)$ & $4(80.0)$ & $1(20.0)$ & & $9(6.8)$ & $1(11.1)$ & $3(33.3)$ & $4(44.5)$ & 1 (11.1) \\
\hline \multicolumn{10}{|l|}{ Mammography } \\
\hline $\begin{array}{l}\text { Lesion } \\
\text { detected }\end{array}$ & $30(83.3)$ & $25(83.3)$ & $3(10.0)$ & $2(6.7)$ & 39 (29.5) & $12(30.8)$ & $10(25.6)$ & $13(33.3)$ & $4(10.3)$ \\
\hline $\begin{array}{c}\text { Lesion not } \\
\text { detected }\end{array}$ & $5(13.9)$ & $5(100)$ & & & $24(18.2)$ & $11(45.8)$ & $10(41.7)$ & $3(12.5)$ & \\
\hline $\begin{array}{l}\text { Not per- } \\
\text { formed } \leq 40 \\
\text { years }\end{array}$ & $0(0.0)$ & & & & $40(30.3)$ & 7 (17.5) & $6(15.0)$ & $26(65.0)$ & $1(2.5)$ \\
\hline Missing & $1(2.8)$ & $1(100)$ & & & $29(22.0)$ & $5(17.2)$ & $15(51.8)$ & $8(27.6)$ & $1(3.4)$ \\
\hline
\end{tabular}

*False negative, ${ }^{+}$False positive, ${ }^{\dagger}$ Missed cancers, ${ }^{\dagger}$ Benign lesion not revealed 
(Table 3). None of the cancers missed by either of the scanning methods were palpable. This results in cancer miss rate of $5.6 \%$ for either method (Table 4). A sensitivity of $88.9 \%$ was calculated for r-US and for m-US (Table 4).
Table 3 False-negative lesions and lesions missed by either scanning method

\begin{tabular}{|c|c|c|c|c|}
\hline Histology & $\begin{array}{l}\text { Meander-like } \\
\text { ultrasound }\end{array}$ & Radial ultrasound & Lesion palpable & $\begin{array}{l}\text { Lesion detected by } \\
\text { mammography }\end{array}$ \\
\hline \multicolumn{5}{|c|}{ False negative lesions } \\
\hline DCIS & BI-RADS 3 & BI-RADS 3 & No & Yes \\
\hline Inv. ductal & BI-RADS 3 & BI-RADS 3 & Yes & Yes \\
\hline \multicolumn{5}{|c|}{ Cancers which were missed by one method } \\
\hline Inv. ductal & Missed & BI-RADS 4 & No & Yes \\
\hline Inv. ductal & Missed & BI-RADS 4 & No & Yes \\
\hline Inv. ductal & BI-RADS 4 & Missed & No & No \\
\hline Inv. ductal & BI-RADS 4 & Missed & No & No \\
\hline \multicolumn{5}{|c|}{ Benign lesions which were missed by one method } \\
\hline B3-Lesion & Missed & BI-RADS 3 & No & Yes \\
\hline Fibrosis & BI-RADS 4 & Missed & No & Yes \\
\hline Fibroadenoma & BI-RADS 3 & Missed & No & No mammography \\
\hline Fibroadenoma & BI-RADS 3 & Missed & No & No mammography \\
\hline
\end{tabular}

Table 4 Diagnostic accuracy of conventional meander-like ultrasound and radial ultrasound

\begin{tabular}{|c|c|c|c|c|c|c|c|c|}
\hline & \multicolumn{3}{|c|}{ Meander-like ultrasound } & \multicolumn{3}{|c|}{ Radial ultrasound } & \multirow[t]{2}{*}{$p$ value } & \multirow[t]{2}{*}{ CI } \\
\hline & $n$ & $\%$ & $\mathrm{CI}$ & $n$ & $\%$ & CI & & \\
\hline Malignant lesions & 36 & 100 & & 36 & 100 & & & \\
\hline Cancers identified & 34 & 94.4 & {$[81.4 ; 99.0]$} & 34 & 94.4 & {$[81.4 ; 99.0]$} & 1 & {$[0.1 ; 13.8]$} \\
\hline Cancers missed & 2 & 5.6 & {$[1.0 ; 18.6]$} & 2 & 5.6 & {$[1.0 ; 18.6]$} & 1 & {$[0.1 ; 13.8]$} \\
\hline True positive & 32 & 88.9 & {$[74.2 ; 96.1]$} & 32 & 88.9 & {$[74.2 ; 96.1]$} & 1 & {$[0.1 ; 13.8]$} \\
\hline False negative $^{\mathrm{a}}$ (BI-RADS 3) & 2 & 5.6 & {$[1.0 ; 18.6]$} & 2 & 5.6 & {$[1.0 ; 18.6]$} & 1 & {$[0.0 ; 13.8]$} \\
\hline False negative ${ }^{\mathrm{b}}$ (BI-RADS 3 and missed cancers ${ }^{\mathrm{c}}$ ) & 4 & 11.1 & {$[3.9 ; 25.8]$} & 4 & 11.1 & {$[3.9 ; 25.8]$} & 1 & {$[0.1 ; 13.8]$} \\
\hline Benign lesions & 132 & 100 & & 132 & 100 & & & \\
\hline Benign lesions identified & 131 & 99.2 & {$[96.1 ; 100.0]$} & 129 & 97.7 & {$[93.7 ; 99.4]$} & 0.63 & {$[0.0 ; 4.2]$} \\
\hline Benign lesions missed & 1 & 0.8 & {$[0.0 ; 3.9]$} & 3 & 2.3 & {$[0.6 ; 6.3]$} & 0.63 & {$[0.0 ; 4.2]$} \\
\hline True negative & 113 & 85.6 & {$[78.6 ; 90.8]$} & 115 & 87.1 & {$[80.5 ; 92.1]$} & 0.79 & {$[0.2 ; 2.5]$} \\
\hline False positive $^{\mathrm{d}}$ (BI-RADS 4 or 5$)$ & 18 & 13.6 & {$[8.4 ; 20.6]$} & 14 & 10.6 & {$[6.2 ; 16.8]$} & 0.39 & {$[0.5 ; 9.1]$} \\
\hline False positive $^{\mathrm{d}}$ (BI-RADS 4 or 5 and missed lesions ${ }^{\mathrm{e}}$ ) & 19 & 14.4 & {$[9.2 ; 21.4]$} & 17 & 12.9 & {$[7.9 ; 19.5]$} & 0.79 & {$[0.2 ; 2.5]$} \\
\hline \multicolumn{9}{|l|}{ Diagnostic accuracy } \\
\hline Sensitivity & & 88.9 & {$[74.2 ; 96.1]$} & & 88.9 & [74.2; 96.1] & 1 & {$[0.1 ; 13.8]$} \\
\hline Specificity & & 86.4 & {$[79.4 ; 91.6]$} & & 89.4 & {$[83.2 ; 93.8]$} & 0.39 & {$[0.1 ; 1.9]$} \\
\hline Accuracy & & 86.9 & {$[81.1 ; 91.6]$} & & 89.3 & {$[83.8 ; 93.4]$} & 0.45 & {$[0.2 ; 1.8]$} \\
\hline $\mathrm{PPV}^{\mathrm{f}}$ & & 64.0 & {$[50.0 ; 76.4]$} & & 69.6 & {$[54.4 ; 82.2]$} & 0.90 & {$[0.25 ; 3.38]$} \\
\hline $\mathrm{NPV}^{\mathrm{g}}$ (excluding missed cancers) & & 98.3 & {$[94.2 ; 99.7]$} & & 98.3 & {$[94.4 ; 99.7]$} & 0.45 & {$[1.0 ; 1.0]$} \\
\hline $\mathrm{NPV}^{\mathrm{g}}$ (including missed cancers) & & 96.6 & {$[91.8 ; 98.8]$} & & 96.7 & {$[92.1 ; 98.9]$} & 0.95 & {$[0.97 ; 1.03]$} \\
\hline
\end{tabular}

${ }^{a}$ The same two breast lesions were classified as BI-RADS 3 by both methods

${ }^{b}$ False negative and NPV were calculated excluding and including missed cancers and ${ }^{\mathrm{d}}$ false positive was calculated excluding and including missed lesions ${ }^{\mathrm{e}}$. In general, studies do not include a second US examination and thus, the cancer miss rate and the number of missed benign lesions remain unknown. Consequently, missed cancers/missed benign lesions are not represented in the calculation of false negative/false positive values and NPV

${ }^{\mathrm{c}}$ Cancers missed by one method but correctly identified by the other

${ }^{\mathrm{e}}$ Benign lesions not revealed by one of the two methods

${ }^{\mathrm{f}} \mathrm{PPV}$, positive predictive value; ${ }^{\mathrm{g}} \mathrm{NPV}$, negative predictive value 
The false positive rate was $13.6 \%(n=18)$ for $\mathrm{m}$-US and $10.6 \%(n=14)$ for $\mathrm{r}$-US with a specificity of 86.4 and $89.4 \%$, respectively (Table 4). Among the benign lesions, ten were falsely classified as BI-RADS four or BI-RADS five by both methods. Additionally, m-US classified 8, and r-US 4 benign lesions as BI-RADS 4 or 5, while they were correctly identified as benign by the other method. The number of benign lesions not revealed were one $(0.8 \%)$ for m-US and three (2.3\%) for r-US. Benign lesions which were missed by either of the scanning methods are listed in Table 3.

The diagnostic accuracy is similar for $\mathrm{r}$-US and $\mathrm{m}$-US. To evaluate whether one of the methods offers potential patient benefits, we compared the average time needed for a bilateral whole breast examination (Table 5).

The overall duration of examinations revealing suspicious lesions was $22.6 \mathrm{~min}$ for $\mathrm{m}$-US while a significantly shorter length of $14.8 \mathrm{~min}$ was found for r-US $(p<0.01)$. As shown in Table 5, the trend of a faster examination by r-US was observed independent of lesion histology. Moreover, the overall examination time in study patients whose US did not reveal a suspicious lesion was $13.3 \mathrm{~min}$ for $\mathrm{m}$-US and $7.6 \mathrm{~min}$. In addition, comparison of the examination time and diagnostic performance for the first versus the last 50 r-US of suspicious lesions revealed that the r-US examiner became more versed with regard to examination time at no loss of diagnostic accuracy (Table 6).

These data corroborate that the r-US is significantly shorter than m-US, independent of whether or not a lesion was detected.

\section{Discussion}

To the best of our knowledge, this study represents the first direct comparison of $\mathrm{m}$-US and $\mathrm{r}$-US. While the diagnostic accuracy of r-US and m-US regarding the detection of breast lesions were comparable, we found that the average examination time for a whole bilateral breast ultrasound

Table 5 Duration of bilateral meander-like ultrasound versus radial ultrasound examination

\begin{tabular}{|c|c|c|c|}
\hline & Meander-like ultrasound & Radial ultrasound & $p$ value \\
\hline $\begin{array}{l}\text { Mean examination duration revealing suspicious lesions requiring breast } \\
\text { biopsy (min) }\end{array}$ & 22.6 & 14.8 & $<0.01$ \\
\hline$(\min , \max )[ \pm \mathrm{SD}]$ & $(4.7,74.0)[ \pm 12.8]$ & $(3.9,47.0)[ \pm 7.6]$ & \\
\hline Malignant lesions & 26.6 & 14.8 & $<0.01$ \\
\hline$(\min , \max )[ \pm \mathrm{SD}]$ & $(4.7,69.0)[ \pm 18.0]$ & $(3.9,38.5)[ \pm 7.1]$ & \\
\hline Benign lesions & 21.7 & 14.8 & $<0.01$ \\
\hline$(\min , \max )[ \pm \mathrm{SD}]$ & $(7.1,74.0)[ \pm 11.2]$ & $(5.2,47.0)[ \pm 7.8]$ & \\
\hline Mean examination duration revealing no or no suspicious lesions (min) & 13.3 & 7.6 & $<0.01$ \\
\hline$(\min , \max )[ \pm \mathrm{SD}]$ & $(2.0,58.2)[ \pm 6.2]$ & $(2.3,64.2)[ \pm 5.8]$ & \\
\hline No lesion detected & 9.7 & 4.0 & $<0.01$ \\
\hline$(\min , \max )[ \pm \mathrm{SD}]$ & $(4.2,22.2)[ \pm 3.8]$ & $(2.3,9.5)[ \pm 1.3]$ & \\
\hline 1 lesion detected & 13.2 & 6.6 & $<0.01$ \\
\hline$(\min , \max )[ \pm \mathrm{SD}]$ & $(4.7,32.3)[ \pm 5.9]$ & $(2.4,24.5)[ \pm 3.3]$ & \\
\hline$>1$ lesion detected & 14.6 & 9.3 & $<0.01$ \\
\hline$(\min , \max )[ \pm \mathrm{SD}]$ & $(2.0,58.2)[ \pm 6.6]$ & $(2.7,64.2)[ \pm 6.8]$ & \\
\hline Mean examination duration of all examinations (min) & 15.0 & 8.9 & $<0.01$ \\
\hline$(\min , \max )[ \pm \mathrm{SD}]$ & $(2.0,74.0)[ \pm 8.6]$ & $(2.3,64.2)[ \pm 6.7]$ & \\
\hline
\end{tabular}

Table 6 Comparison of the first and last 50 radial ultrasound examinations revealing suspicious lesions

\begin{tabular}{llll}
\hline & $\begin{array}{l}\text { First 50 radial } \\
\text { ultrasound examinations }\end{array}$ & $\begin{array}{l}\text { Last 50 radial } \\
\text { ultrasound examinations }\end{array}$ & $p$ value \\
\hline $\begin{array}{l}\text { Duration of radial ultrasound examination } \\
\text { Mean time (min) }\end{array}$ & 19.8 & 9.9 & $<0.01$ \\
$($ min, max) $[ \pm \mathrm{SD}]$ & $(5.2,47.0)[ \pm 8.6]$ & $(3.9,17.6)[ \pm 3.4]$ & \\
Diagnostic accuracy & & & 0.45 \\
Sensitivity [CI] & $70.0[38.1 ; 91.3]$ & $91.7[63.4 ; 99.6]$ & 1 \\
Specificity [CI] & $90.0[76.8 ; 96.5]$ & $86.8[72.8 ; 94.7]$ & 1 \\
Accuracy [CI] & $86.0[73.4 ; 93.7]$ & $88.0[76.4 ; 94.6]$ & \\
\hline
\end{tabular}


was significantly shorter for $\mathrm{r}$-US than for m-US for all patients independent of whether or not a suspicious lesion was detected.

In our study, 36 breast cancers were diagnosed out of 1948 combined US examinations. This results in a cancer detection rate of $1.8 \%$. Under similar conditions, i.e. an unselected mixed study collective, cancer detection rates ranging from 0.83 [18] to $3.2 \%$ [19] have been reported. For m-US, we found a sensitivity of $88.9 \%$ and a specificity of $86.4 \%$ which is within the range of previously reported values [18-21]. A recent meta-analysis [22] published a sensitivity of $87 \%$ and specificity of $72 \%$. It is noteworthy that for r-US, we observed an equally high sensitivity, while the specificity was slightly higher than for $\mathrm{m}$-US $(89.4 \%$ versus $86.4 \%)$.

The diagnostic accuracy of r-US was $89.3 \%$ which corresponds to the highest values found for m-US [19, 20]. Similarly, PPV (69.6\%) and NPV (98.3\%) for r-US were in the range compared to published m-US data $[20,21$, 23-25].

The only values published for r-US that we are aware of represent combined data from r-US and mammography [9]. Nevertheless, sensitivity (90.3\%), specificity (78.5\%), and diagnostic accuracy (81.8\%) compare reasonably well to our data $(88.9,89.4$, and $89.3 \%$, respectively). The falsenegative rate of r-US in combination with mammography (9.7\%) was higher than what we found for $\mathrm{r}$-US alone (5.6\%). Although the false-negative rates for m-US vary in the literature $(3.6-7.5 \%)[20,25,26]$, we found the same value for $\mathrm{r}$-US and $\mathrm{m}$-US (5.6\%). Two lesions were wrongly classified as BI-RADS 3 lesions by $\mathrm{m}$-US and r-US, while histology revealed a DCIS and an invasive ductal triple negative breast cancer. It is conceivable that triple negative breast cancers may be wrongly classified because their sonographic appearance often lacks malignant features [27].

Two malignancies were not detected by m-US and two others were not detected by r-US (Table 3 ). However, each of them was identified by the other method which results in a cancer miss rate of $5.6 \%$ for either method. One of the carcinomas missed by $\mathrm{r}$-US was localized in the upper outer quadrant close to the axilla. This emphasizes the importance to also sweep the outer upper quadrant with the radial probe. The number of benign lesions not revealed by one, but by the other method was one $(0.8 \%)$ for m-US, and three (2.3\%) for r-US. Overall, in our study $98.2 \%$ of all lesions were detected by m-US and $97.0 \%$ by r-US. In comparison, Kim et al. reported a detection rate of $93.9 \%$ for m-US [28]. According to Berg et al. [29], individual examiners detected between 49 and $66 \%$ of the lesions by m-US. In a breast phantom study [30], a median of 14 out of 17 lesions (82\%) were detected. The detection rate of $97.0 \%$ for $\mathrm{r}-\mathrm{US}$ is similar to our detection rate for m-US and higher than the published rates for $\mathrm{m}$-US.
The mean examination time for a bilateral whole breast m-US was $13.3 \mathrm{~min}$ for patients without or with unsuspicious breast lesions, and $22.6 \mathrm{~min}$ for patients with suspicious breast lesions. Mean examination times of $20.8 \mathrm{~min}$ in a mixed collective (ranging from 2-90 $\mathrm{min}$ ) [31] and $31 \mathrm{~min}$ in patients with three and more lesions (ranging from 3-59 min) [29] have been reported for bilateral m-US. In contrast, the present study reveals a significantly shorter examination time for r-US, which might be related to the increased width of the probe. With a mean examination time of $7.6 \mathrm{~min}$ for patients without or with unsuspicious lesions, and $14.8 \mathrm{~min}$ for patients with suspicious breast lesions. Our data show good agreement with Rosensweig [1] who reported an examination time of $14 \mathrm{~min}$ for r-US. Some examiners might perform meander-like or radial ultrasound only in one plane, which would evidently shorten the examination time. However, in this study, the reported examination time refers to two-plane scanning for $\mathrm{m}$-US and r-US. Thus, we can conclude that in general, radial sonographic breast examination takes less time independent of the histology or the number of breast lesions.

Based on the study design, m-US and r-US could not be carried out by the same examiner, because knowledge of the first US results would bias the second examination, which constitutes a limitation of our study. M-US was performed by experts or supervised inexperienced examiners as it is common in teaching hospitals. Therefore, we cannot exclude that when examiners with less experience performed m-US examinations, times were slightly increased compared to experienced examiners. In addition, not all patients agreed to participate in the study and thus, the study collective may not fully represent the consecutive, mixed population of an outpatient breast clinic. Out of the 1948 dual m-US/r-US examinations, 150 examinations revealed 168 suspicious lesions. Unsuspicious lesions (BI-RADS 3 lesions with no additional risk factors, and BI-RADS 2 lesions) were not biopsied. The absence of proven negative results might be considered a limitation. However, our data reflect examination procedures common to teaching hospitals and routine clinical settings.

Radial ultrasound is a viable alternative to conventional meander-like ultrasound in routine breast examination. Sensitivity, specificity, and false-negative rate of the two methods are comparable. In addition, patients benefit from a significantly shorter examination time.

Acknowledgments We thank Dr. Dominique Amy (Aix en Provence, France) for his dedicated teaching of radial breast ultrasound. The study was funded by the Krebsliga beider Basel, Switzerland (KLBB Nr. 22/2010).

Author contributions CJW: data collection and final approval of the submitted version; PBL: data collection and final approval of the submitted version; SS: data analysis, manuscript editing, and final approval 
of the submitted version RB: data collection, manuscript editing, and final approval of the submitted version CAS: data analysis, manuscript writing, manuscript editing, and final approval of the submitted version; RZD: protocol and project development, data collection, data analysis, manuscript writing, manuscript editing, and final approval of the submitted version.

Funding The study was funded by the Krebsliga beider Basel, Switzerland (KLBB Nr. 22/2010), and was registered under NCT02358837.

\section{Compliance with ethical standards}

Conflict of interest We declare that we have no conflict of interest.

Ethical approval The study was approved by the local ethical committee (Ethikkommission beider Basel: EKBB Nr. 123/11).

Informed consent All study participants signed the informed consent form in accordance with the World Medical Association Declaration of Helsinki.

Open Access This article is licensed under a Creative Commons Attribution 4.0 International License, which permits use, sharing, adaptation, distribution and reproduction in any medium or format, as long as you give appropriate credit to the original author(s) and the source, provide a link to the Creative Commons licence, and indicate if changes were made. The images or other third party material in this article are included in the article's Creative Commons licence, unless indicated otherwise in a credit line to the material. If material is not included in the article's Creative Commons licence and your intended use is not permitted by statutory regulation or exceeds the permitted use, you will need to obtain permission directly from the copyright holder. To view a copy of this licence, visit http://creativecommons.org/licenses/by/4.0/.

\section{References}

1. Rosensweig R, Foy PM, Cole-Beuglet C, Kurtz AB, Goldberg BB (1982) Radial scanning of the breast: an alternative to the standard ultrasound technique. J Clin Ultrasound 10:199-201

2. Da Costa D, Taddese A, Cure ML, Gerson D, Poppiti R Jr, Esserman LE (2007) Common and unusual diseases of the nipple-areolar complex. Radiographics 27(Suppl 1):S65-77

3. Stavros AT (2004) Breast ultasound. Lippincott Williams \& Wilkins, Philadelphia, PA 19106 USA

4. Kim WH, Chang JM, Moon WK, Cho N, Yi A, Koo HR, Kim SJ (2013) Intraductal mass on breast ultrasound: final outcomes and predictors of malignancy. AJR Am J Roentgenol 200:932-937

5. Rissanen T, Reinikainen H, Apaja-Sarkkinen M (2007) Breast sonography in localizing the cause of nipple discharge: comparison with galactography in 52 patients. J Ultrasound Med 26:1031-1039

6. Ballesio L, Maggi C, Savelli S, Angeletti M, Rabuffi P, Manganaro L, Porfiri LM (2007) Adjunctive diagnostic value of ultrasonography evaluation in patients with suspected ductal breast disease. Radiol Med 112:354-365

7. Madjar H, Rickard M, Jellins J, Otto R (1999) IBUS guidelines for the ultrasonic examination of the breast. IBUS International Faculty. International Breast Ultrasound School. Eur J Ultrasound 9:99-102

8. Hooley RJ, Scoutt LM, Philpotts LE (2013) Breast ultrasonography: state of the art. Radiology 268:642-659
9. Ebner L, Bonel HM, Huber A, Ross S, Christe A (2014) Diagnostic performance and additional value of elastosonography in focal breast lesions: statistical correlation between size-dependant strain index measurements, multimodality-BI-RADS score, and histopathology in a clinical routine setting. ISRN Radiol 2014:396368

10. Gheonea IA, Donoiu L, Camen D, Popescu FC, Bondari S (2011) Sonoelastography of breast lesions: a prospective study of 215 cases with histopathological correlation. Rom J Morphol Embryol 52:1209-1214

11. Gheonea IA, Stoica Z, Bondari S (2011) Differential diagnosis of breast lesions using ultrasound elastography. Indian J Radiol Imaging 21:301-305

12. Hooley RJ, Greenberg KL, Stackhouse RM, Geisel JL, Butler RS, Philpotts LE (2012) Screening US in patients with mammographically dense breasts: initial experience with Connecticut Public Act 09-41. Radiology 265:59-69

13. Wojcinski S, Cassel M, Farrokh A, Soliman AA, Hille U, Schmidt W, Degenhardt F, Hillemanns P (2012) Variations in the elasticity of breast tissue during the menstrual cycle determined by real-time sonoelastography. J Ultrasound Med 31:63-72

14. Teboul M (2004) Practical ductal echography; guide to intelligent and intelligible ultrasonic imaging of the breast. Editorial Medgen, S.A. ISBN: 84-609-0190-4

15. (2003) Breast Imaging Reporting and Data System (BI-RADS) Atlas ${ }^{\circledR}, 4$ th edn. American College of Radiology (ACR), Reston, VA

16. Blaker H (2000) Confidence curves and improved exact confidence intervals for discrete distributions. Can J Stat 28:783-798

17. Zhou X-HO, Mcclish DK, Obuchowski NA (2011) Statistical methods in diagnostic medicine. John Wiley \& Sons, Hoboken

18. Lenz S (2011) Breast ultrasound in office gynecology-ten years of experience. Ultraschall Med 32(Suppl 1):S3-7

19. Hille H, Vetter M, Hackeloer BJ (2012) The accuracy of BI-RADS classification of breast ultrasound as a first-line imaging method. Ultraschall Med 33:160-163

20. Farrokh A, Wojcinski S, Degenhardt F (2011) Diagnostic value of strain ratio measurement in the differentiation of malignant and benign breast lesions. Ultraschall Med 32:400-405

21. Redling K, Schwab F, Siebert M, Schotzau A, Zanetti-Dallenbach R (2017) Elastography complements ultrasound as principle modality in breast lesion assessment. Gynecol Obstet Invest 82:119-124

22. Li Q, Hu M, Chen Z, Li C, Zhang X, Song Y, Xiang F (2018) Meta-analysis: contrast-enhanced ultrasound versus conventional ultrasound for differentiation of benign and malignant breast lesions. Ultrasound Med Biol 44:919-929

23. Wojcinski S, Farrokh A, Weber S, Thomas A, Fischer T, Slowinski T, Schmidt W, Degenhardt F (2010) Multicenter study of ultrasound real-time tissue elastography in 779 cases for the assessment of breast lesions: improved diagnostic performance by combining the BI-RADS(R)-US classification system with sonoelastography. Ultraschall Med 31:484-491

24. Stachs A, Hartmann S, Stubert J, Dieterich M, Martin A, Kundt G, Reimer T, Gerber B (2013) Differentiating between malignant and benign breast masses: factors limiting sonoelastographic strain ratio. Ultraschall Med 34:131-136

25. Wang SD, Wang L, Li ZX, Wei KL, Liao XH, Chen YY, Huang X (2017) Differential diagnostic performance of acoustic radiation force impulse imaging in small $(\% 3 \mathrm{c} /=20 \mathrm{~mm})$ breast cancers: is it valuable? Sci Rep 7:8650

26. Ackermann S, Schoenenberger CA, Zanetti-Dallenbach R (2016) Clinical data as an adjunct to ultrasound reduces the false-negative malignancy rate in BI-RADS 3 breast lesions. Ultrasound Int Open 2:E83-89 
27. Wang D, Zhu K, Tian J, Li Z, Du G, Guo Q, Wu T, Li J (2018) Clinicopathological and ultrasonic features of triple-negative breast cancers: a comparison with hormone receptor-positive/ human epidermal growth factor receptor-2-negative breast cancers. Ultrasound Med Biol 44:1124-1132

28. Kim SH, Kang BJ, Choi BG, Choi JJ, Lee JH, Song BJ, Choe BJ, Park S, Kim H (2013) Radiologists' performance for detecting lesions and the interobserver variability of automated whole breast ultrasound. Korean J Radiol 14:154-163

29. Berg WA, Blume JD, Cormack JB, Mendelson EB (2006) Operator dependence of physician-performed whole-breast US: lesion detection and characterization. Radiology 241:355-365

30. Berg WA, Blume JD, Cormack JB, Mendelson EB, Madsen EL, Investigators A (2006) Lesion detection and characterization in a breast US phantom: results of the ACRIN 6666 Investigators. Radiology 239:693-702

31. Berg WA, Blume JD, Cormack JB, Mendelson EB, Lehrer D, Bohm-Velez M, Pisano ED, Jong RA, Evans WP, Morton MJ, Mahoney MC, Larsen LH, Barr RG, Farria DM, Marques HS, Boparai K, Investigators A (2008) Combined screening with ultrasound and mammography vs mammography alone in women at elevated risk of breast cancer. JAMA 299:2151-2163

Publisher's Note Springer Nature remains neutral with regard to jurisdictional claims in published maps and institutional affiliations. 